\title{
Transportation System and Trade Flows in Port Cities of China: A Random Coefficient Model
}

\author{
Lizhi XU \\ School of Economics and Management, University of Chinese Academy of Sciences, Beijing 100190, \\ China; \\ Tourism Institute, Beijing Union University, Beijing 100101, China \\ Shu-Cherng FANG \\ Department of Industrial Engineering, North Carolina State University, Raleigh, NC 27695, USA \\ Kin Keung LAI \\ Department of Management Sciences, City University of Hong Kong, Hong Kong, China \\ Han QIAO ${ }^{\dagger}$ \\ School of Economics and Management, University of Chinese Academy of Sciences, Beijing 100190, \\ China \\ E-mail: qiaohan@ucas.ac.cn

\section{Shouyang WANG} \\ Academy of Mathematics and Systems Science, Chinese Academy of Sciences, Beijing 100190, China

\begin{abstract}
This paper quantitatively investigates the effect of transportation system on trade flows of four major port cities in China. Due to the significant country-pair heterogeneities in both intercept and slope terms, this paper introduced a random-coefficients model for parameters estimation. The empirical findings imply that the impact of the explanatory variables included in the gravity equation could be inaccurately estimated if the pair-wise heterogeneity biases in both intercept and slope terms are not accounted for during the econometric estimation of the model. In particular, in the presence of this heterogeneity, parameter estimates tend to be underestimated for country-pairs with higher trade volume and overestimated for those country-pairs with lower trade volume. In addition, the empirical results suggest that the improvement transportation system in port cities of China offers greater scope
\end{abstract} \\ for its trade competitiveness.
}

Keywords gravity model; random coefficient model; bilateral trade flows; port city

\section{Introduction}

With the sharp rise in China's international and intraregional trade, the coastal areas of China, with geographic advantage in accessing foreign markets and serving as a gateway for

Received June 24, 2015, accepted July 31, 2015

Supported by National Natural Science Foundation of China (71390330, 71390331, 71003057, 71373262); The Postdoctor Foundation of China (2013M541019); Hong Kong RGC (8770001)

$\dagger$ The corresponding author 
trade expansion, have evolved into export-oriented industries agglomeration areas ${ }^{[1]}$. Major port cities in China are becoming the most congested in the world. For example, top eight container ports located in the major port cities of Shanghai, Shenzhen, Qingdao, NingboZhoushan, Guangzhou, Tianjin, Xiamen and Dalian, have been ranked among the global top 30 container terminals, in terms of throughput, since 2006 . They handle about $80 \%$ container cargoes in China and more than $75 \%$ of its export cargos are transported through them. In addition, seven of these port cities are located in China's three main regions - The Yangtze River Delta (YRD), the Pearl River Delta (PRD) and the Bohai Bay Areas (BBA). They are the main industrial, manufacturing, as well as export bases in China, accounting for more than two-third of China's trade volumes ${ }^{[2]}$. It is quite important therefore, to analyze factors that matter the most to the trade flows in port cities of China. More importantly, with the building up pressure on having efficient and sufficient transport networks in those cities, it is also important to provide an econometric framework to analyze the effect of transportation system on trade flows of Chinese port cities.

In discussing trade flows between countries, the gravity model of trade is typically used for estimating the impact of a variety of factors in the literature. In particular, being identified as the key determinants for international trade flows, there is a growing mass of literature covering the degree and nature of the effects of transportation system on the trade flows of different countries and regions. For instance, by specifying the gravity model, Limão and Venables ${ }^{[3]}$ confirmed that transport and other costs of doing business internationally are important determinants of a country's ability to participate fully in the world economy. Being landlocked, they concluded, raises costs by $\$ 3,450$, compared to a mean cost of $\$ 4,620$ for non-landlocked countries. Furthermore, Irwin and Terviö ${ }^{[4]}$ concluded that a country's geographic characteristics have large positive impact on trade and income. Maritime transport cost is another important determinant of the overall transport costs. In addition, Bougheas, Demetriadesb and Morgenrothc ${ }^{[5]}$ evaluated the effect of public infrastructure on trade flows by using a direct measure of transport infrastructure, namely, the length of motorway network. They concluded that the differences in volume and quality of infrastructure across countries are responsible for differences in transport costs.

On the basis of the same standard gravity model, another growing mass of literature has documented the impact of transportation efficiency on the volume of trade. Wilson et al. ${ }^{[6]}$ defined and analyzed the impact of reform of four different categories of trade facilitation: Port efficiency, customs environment, customs regulatory environment and service infrastructure. They concluded that port and efficient infrastructures are the main trade facilitation indicators affecting trade expansion. Clark et al. ${ }^{[7]}$ used survey measures of port efficiency drawn from the Global Competitiveness Report to examine the relationship between port efficiency and international trade flows. The estimation results show that improving port efficiency from the 25 th to the 75 th percentile reduces shipping costs by $12 \%$. Furthermore, Xu, Fang and Zhang ${ }^{[2,8]}$ quantitatively investigated and estimated the impact of port efficiency on China's trade. Their findings suggested that the inadequacy and inefficiency port facilities and related services have become even more serious obstacles to the growth of China's foreign trade.

The purpose of this paper is to quantitatively investigate the effect of transportation system 
on trade flows of four major port cities in China. In light of the fact that country-pair heterogeneities in both intercept and slope terms are important factors in explaining bilateral trade flows between China and other countries. This paper introduced a random-coefficients model for parameters estimation, which allows for modeling the heterogeneity in the functional relationship between dependent variable and independent variables. The empirical findings suggest that unless heterogeneity is accounted for correctly in both intercept and slope terms, standard gravity models could yield biased results.

The rest of this paper is organized as follows. Section 2 presents theoretical gravity model specification and empirical model specification — The random-coefficients model for parameter estimations. The results of empirical analysis are reported in Section 3. Some conclusions and implications are presented in Section 4.

\section{Model Specification and Empirical Analysis}

In this section, we first introduce and expand a dominant theoretical framework for analyzing bilateral trade flows - The gravity model of trade. Secondly, based on random-coefficients model for parameter estimations, we empirically investigate the implications of transport costs and port efficiency for China's exports.

\subsection{Theoretical Gravity Model Specification}

First developed by Tinbergen ${ }^{[9]}$, the gravity equation predicts bilateral trade flows based on trading partners' economic sizes, typically measured by Gross Domestic Product (GDP), population or GDP per capita, and geographical distance between two units. It has been successfully employed to evaluate the impact of various factors, such as the regional free trade agreements, exchange rate variability, adjacency, island or landlocked, common language, tariff and other institutional and political trade barriers.

In the panel date version, most researchers follow three-way fixed effects specification of the bilateral gravity model as proposed by Egger and Pfaffermayr ${ }^{[10]}$, which includes main countryspecific effects, time-specific effects, as well as time invariant exporter-by-importer interaction effects. This restricted version of the general gravity model is a more appropriate specification since it can account for a large part of variations, in addition to other explanatory variables ${ }^{[10]}$. Specifically, the exporter and importer effects control for all time-invariant observable and unobservable country-specific characteristics, like the geographical, historical, political and cultural time invariant characteristics ${ }^{[11-13]}$. Time effects capture cyclical influences commonly shared by all involved countries. Time invariant country-pair interaction effects allow for the intercepts of the gravity equation to be specific to each trading pair that controls for the pair-wise heterogeneity. In short, from the econometric perspective, the use of this standard gravity model specification could overcome the shortcomings of the cross-section specification, such as omitted variables, multicollinearity and so forth ${ }^{[14-15]}$. Following Egger ${ }^{[10,15]}$, most log-linearized equations of the three-way fixed effects gravity model in the literatures specifically take the following form:

$$
\ln \left(E X_{i j t}\right)=\alpha_{0}+\alpha_{1} \ln \left(X_{i t}\right)+\alpha_{2} \ln \left(X_{j t}\right)+\alpha_{3} \ln \left(Y_{i t}\right)+\alpha_{4} \ln \left(Y_{j t}\right)
$$




$$
+\sum_{k=1}^{K} \gamma_{k} \ln \left(C_{i j t}^{k}\right)+\beta_{i}+\beta_{j}+\beta_{t}+\beta_{i j}+\nu_{i j t}
$$

where the subscripts of $i, j$ and $t$ stand for the exporter, importer and the time period, respectively. $E X_{i j t}$ represents volume of trade from exporter $i$ to importer $j$ at time $t . X_{i(j) t}$ and $Y_{i(j) t}$ denote the GDP and population (or GDP per capita), respectively. $\left\{C_{i j t}^{k}, k=1,2, \cdots, K\right\}$ stand for a set of variables with which trade barriers are associated. $\alpha_{0}$ is a constant to be estimated and $\alpha_{1}, \alpha_{2}, \alpha_{3}$ and $\alpha_{4}$ are the elasticity to be estimated (expected to be positive). $\gamma_{k}$ is expected to be negative. $\beta_{i}$ and $\beta_{j}$ denote the unobservable individual-specific effects of exporter $i$ and importer $j$, respectively. $\beta_{i j}$ is the pair-wise unique unobservable trade relationships between exporter and importer. $\beta_{t}$ is specific to time $t$ and used to capture the common business cycle or globalization process over the whole sample of countries. Finally, $\nu_{i j t}$ is a random disturbance assumed to be normally distributed.

The panel econometric specification of the gravity equation is extended to model the trade flows from China's major export markets to its export destinations. The exporter $i$ in Equation (1) is specified as different export markets of China. As for the term $\sum_{k=1}^{K} \gamma_{k} \ln \left(C_{i t}^{k}\right)$, following $\mathrm{Xu}$, Fang and Zhang ${ }^{[2,8]}$, it is specified as three components. The Equation (1) can be rewritten as follows:

$$
\begin{aligned}
\ln \left(E X_{i j t}\right)= & \alpha_{0}+\alpha_{1} \ln \left(X_{i t}\right)+\alpha_{2} \ln \left(X_{j t}\right)+\alpha_{3} \ln \left(Y_{i t}\right)+\alpha_{4} \ln \left(Y_{j t}\right) \\
& +\gamma_{1} \ln \left(T_{i t}\right)+\gamma_{2} \ln \left(R_{i t}\right)+\gamma_{3} \ln \left(C T_{i t}\right)+\beta_{j}+\beta_{t}+\nu_{i j t}
\end{aligned}
$$

where $T_{i t}$ and $R_{i t}$ denote the total volume of freight carried by train and by road by exporter $i$ at time $t$, respectively. $C T_{i t}$ denotes the total container throughput of port $i$ at time $t$. $\gamma_{1}, \gamma_{2}$ and $\gamma_{3}$ are the elasticity to be estimated, respectively. The signs of $\gamma_{1}$ and $\gamma_{2}$ are expected to be negative. The sign of $\gamma_{3}$ is expected to be positive as the more cargo a port handles in a given time, the higher is the port efficiency and hence the lower is the fixed cost

for a port ${ }^{[7]}$. In addition, the exporter dummy variable $\beta_{i}$ is exempted from the equation for avoiding multicollinearity problem. Also, the pair-wise variable $\beta_{i j}$ is excluded since all trade data in our samples are joint trading pairs ${ }^{[2,8]}$. As such, Equation (2) is our theoretical gravity specification used to investigate the effects of transport system on trade flows in the port cities of China.

\subsection{Random-Coefficients Model}

A random-coefficients model, first developed by Swamy ${ }^{[16]}$, is to treat the parameter vector as a realization (in each panel) of a stochastic process. It can be expressed as the following model:

$$
y_{i}=X_{i} \beta_{i}+\varepsilon_{i}
$$

where $i=1,2, \cdots, m$. Both $\beta_{i}$ and $\varepsilon_{i}$ are unobserved random vectors, and $\beta_{i}$ is the coefficient vector specific to the $i$ th cross-sectional unit. And, $\beta_{i}=\beta+v_{i}, E\left(v_{i}\right)=0$ and $E\left(v_{i} v_{i}^{\prime}\right)=\Sigma$. Such that we have

$$
y_{i}=X_{i}\left(\beta+v_{i}\right)+\varepsilon_{i}=X_{i} \beta+\left(X_{i} v_{i}+\varepsilon_{i}\right)=X_{i} \beta+\omega_{i}
$$


where $E\left(\omega_{i}\right)=0$ and $E\left(\omega_{i} \omega_{i}^{\prime}\right)=\sigma_{i}^{2} I+X_{i} \Sigma X_{i}^{\prime}=\Pi_{i}$. Accordingly, the GLS estimator of $\hat{\beta}$ is then

$$
\hat{\beta}=\left(\sum_{i} X_{i}^{\prime} \Pi_{i}^{-1} X_{i}\right)^{-1} \sum_{i} X_{i}^{\prime} \Pi_{i}^{-1} y_{i}
$$

The variance of $\hat{\beta}$ is

$$
\operatorname{Var}(\hat{\beta})=\sum_{i=1}^{m}\left(\Sigma+\sigma_{i}^{2}\left(X_{i}^{\prime} X_{i}\right)^{-1}\right)^{-1}
$$

Swamy ${ }^{[16]}$ suggested that the unknown $\Sigma$ and $\sigma_{i}$ parameters can be estimated using the two-step approach.

\subsection{Empirical Gravity Model Specification Based on Random-Coefficients Model}

In the above Equation (2), the three-way fixed effects gravity equation is extended to model the trade flows from China's major export markets to its export destinations. In this panel econometric specification, it removes the restrictions that the intercept terms are common to every country pairs and over time in the sample. This specification could effectively eliminate heterogeneity bias in the intercept terms, which is inherent in standard econometric methods. However, to investigate the effect of transportation system on the trade flows in port cities of China, there are other country-pair heterogeneity characteristics from China's specific trade patterns.

Specifically, China's export trade pattern in recent decades kept changing and was increasingly importing from Asia and exporting to developed economies, largely the United States and Europe. Meanwhile, China's export trade pattern with Asian country was substantially changing with the intraregional trade. Those participating in international processing activities trade more with other production countries, like China. For example, the share of total imports from Japan and Hong Kong has decreased from about 21.96 and 6.5 percent in 1995 to 15.21 and 1.85 percent respectively. Shares of the China's exports to Japan and Hong Kong have decreased over the same period from 19.13 percent to 11.02 percent, and from 24.19 percent to 16.34 percent, respectively ${ }^{[2]}$. In contrast, some Asian countries, like Malaysia and Thailand are among the most important export destinations of China ${ }^{[17]}$. As a result, variations caused by the new trade characteristics may lead to the parameter heterogeneity for different China's export destination. Also, the variations from China-to-Asia trade may lead to the parameter estimation weighted to Asian region.

In addition, those country-pair heterogeneity characteristics from China's specific trade patterns are significant in our sample. For importing countries in our sample, there are 10 countries and Hong Kong from Asia, 16 countries form Europe, 4 countries from America. Among the ten Asian countries, three trade partners - Hong Kong, Japan and Korea is on the top ten exporters of China. In our sample, the export value to three Asian destinations from four cities is $95931.3,32568.3$ and 13652.5 million dollars respectively in 2008. The total value of export to Asia in our sample is 170032 million dollars, which is significant larger than that to Europe 55110.1 and to America 94709.4 million dollars ${ }^{[2]}$. Thus, the sample is weighted toward Asian countries, which may make the parameter heterogeneity for different China's export destinations more seriously. 
In light of the analysis above, the country-pair heterogeneity in the data should be taken into account in the econometric estimation of the gravity equation. With such heterogeneity, China may trade different amounts from two other countries belonging to different regions even though the two markets have the same GDP and are equidistant from each other. It may happen due to historical, cultural, political or geographical factors, which could affect the level of bilateral trade flows and be correlated with the independent variables included in the gravity equation ${ }^{[18]}$. Therefore, it is logical to assume that the impact of the explanatory variables included in the gravity equation is not affecting uniformly bilateral trade flows among country-pairs.

Although the specification of Equation (2) could eliminate heterogeneity bias in the intercept terms, it still maintains the restriction that the slope coefficients are constant across country pairs. In other words, the impact of the explanatory variables on bilateral trade flows is the same among country-pairs. As the analysis above, China's diversified trade patterns as unobservable factors in gravity model strongly influence the response of variables in our model. In such case, it is necessary in a model specification to account for the impact of these factors in bilateral trade flows in the empirical estimation of the gravity equation, which can better eliminates heterogeneity bias inherent in our standard econometric methods.

As we show in Equation (3), a random-coefficients model proposed for parameters estimation allows for modeling the heterogeneity in the functional relationship between dependent variable and independent variables. Tzouvelekas ${ }^{[18]}$ argued that if these factors vary among countrypairs but are unobserved, regarding $\beta$ 's as the means of a random response may be better than assuming that these are constant. On the basis of random-coefficient model in the Equation (3), the above Equation (2) can be reset as follows:

$$
\begin{aligned}
\ln \left(E X_{i j t}\right)= & \alpha_{0 j}+\alpha_{1 j} \ln \left(X_{i t}\right)+\alpha_{2 j} \ln \left(X_{j t}\right)+\alpha_{3 j} \ln \left(Y_{i t}\right)+\alpha_{4 j} \ln \left(Y_{j t}\right) \\
& +\gamma_{1 j} \ln \left(T_{i t}\right)+\gamma_{2 j} \ln \left(R_{i t}\right)+\gamma_{3 j} \ln \left(C T_{i t}\right)+\beta_{t}+\nu_{i j t}
\end{aligned}
$$

As such, Equation (7) is the empirical gravity specification used to estimate the effects of transportation system on export trade flows in the port cities of China.

\section{Estimations and Empirical Analysis for the Extended Gravity model}

Models are estimated by using the annual data set, which contains 948 observations and involves a balanced panel of four port cities export to 32 other countries and Hong Kong Area, Mainland of China over the period of 1997-2008. Four port cities are Shanghai of Yangtze River Delta (YRD), Shenzhen and Guangzhou of Pearl River Delta (PRD) and Tianjin of Bohai Bay Area (BBA). Other port cities are not included in our model in part because of the availability and consistency of data. In another, it is also because of the fact that four cities are form three major manufacturing bases of China and are representative.

Available data include the annual export value of four port cities to their trade partners (in constant 1995 US\$), the annual data of real GDP of exporter (in constant $1995 \mathrm{RMB}$ ) and importer (in constant 1995 US\$), GDP per capita, the average wage and population of four port cities, GDP per capita of importing countries, the annual container throughput of four ports, and the aggregated freight volume carried by both railroad and highway mode in terms of tonnage. All the data used in this analysis originally come from the China Customs General 
Administration, the National Bureau of Statistics, the China Customs, the China Statistical Yearbook, and CEIC China Database.

With large panel datasets and in light of the present of parameter heterogeneity, we fit a random-coefficients model for parameter estimation. The generalized least squares estimating results of the random-coefficients gravity model are reported in Table 1. In addition, Johnston and DiNardo ${ }^{[19]}$ provided a test to look at the difference between the OLS estimate of parameters ignoring the panel structure of the data and the matrix-weighted average of the panel-specific OLS estimators. As presented in Table 1, calculated chi-square statistic is 1482.61, well above the corresponding critical value at the $1 \%$ level of significance. The test statistics significantly reject the assumption of parameter constancy, indicating the empirical support for the stochastic varying coefficient gravity model specification. It implies that such parameter variation across country pairs could still be likely to provide biased estimates.

Generally, the signs of estimated parameters of explanatory variables widely conform to the previous theoretical results. Wald-type tests confirm the joint statistical significance of all the non-constant variables at $1 \%$ significance level. In addition, we also carry out the test for collinearity problem. By detecting the collinearity of the regressors with the constant, we rule out all the variables that may cause the serious collinearity problem. The computation results present that the mean variance inflation factor (VIF) of all variables in our model is 4.11. Values in excess of 20 are suggested as indicative of a problem ${ }^{[20]}$. Specifically, given these regressors are in logarithm form, coefficients of these regressors can be interpreted as elasticity. The sign of exporter's GDP is positive and statistically significant at $1 \%$ level in random-coefficients model. Baier and Bergstrand ${ }^{[21]}$ stated that for an exporting country, exporter GDP can be interpreted in the gravity trade model as its production capacity. The coefficient of importer's GDP is 0.83 and positive and statistically significant at $1 \%$ level. They are in line with the results in literature.

For the purposes of comparison, we also examine the extended gravity model on China's main export destination: Asia, Europe and America on the basis of three sub-sets of our sample. The estimation results and diagnostic tests with the $p$-value for three gravity models are reported in the Columns $4 \sim 8$ of Table 1 . According to tests results, we perform Hoechle ${ }^{[22]}$ program to estimate the extended gravity model of three export regions. This nonparametric covariance matrix estimator produces heteroscedasticity- and autocorrelation-consistent standard errors that are robust to general forms of spatial and temporal dependence. As expected, the variation of the parameter estimates among Asia, Europe and America sub-sets gravity model is substantial. It implies that the coefficient estimations in three models significantly support the parameter heterogeneity of different export regions.

As it is shown in Table 1, the parameter estimates of the independent variables among three sub-sets models have significant variations due to the existence of pair-wise heterogeneity. Especially, the econometric estimates of three sub-sets gravity are different in terms of both the magnitudes and the signs of the importing country's GDP per capita and GDP. Specifically, the parameter estimate for importing country's GDP per capita ranges from -0.18 to 1.23 , for importing country's GDP from -0.23 to 1.02. Also, the differences in the magnitude of parameter estimates are significant and evident for other independent variables, although their 
signs remain the same among different models. For example, the contribution of independent variable like exporting country's GDP per capital to bilateral trade flows in port cities of China vary significantly across Asia, Europe and America trade partners, ranging from -0.91 for Asia to -0.29 for Europe.

Table 1 Estimation results of the extended gravity equations

\begin{tabular}{|c|c|c|c|c|c|c|c|c|}
\hline \multirow{2}{*}{$\begin{array}{l}\text { Variables } \\
\text { GDP exporter }\end{array}$} & \multicolumn{2}{|c|}{$\begin{array}{c}\text { Random-coefficient } \\
\text { Model }\end{array}$} & \multicolumn{2}{|c|}{ Asia Model } & \multirow[t]{2}{*}{ Europe } & Model & \multicolumn{2}{|c|}{ America Model } \\
\hline & $1.24^{* * *}$ & $(2.87)$ & $0.76^{* * *}$ & $(6.62)$ & & $(7.24)$ & $1.00 * * *$ & $(4.34)$ \\
\hline GDP pc exporter & $-0.36^{* * *}$ & $(-2.90)$ & $-0.91^{* * *}$ & $(-5.66)$ & $-0.29 * * *$ & $(-3.27)$ & $-0.39^{*}$ & $(-2.00)$ \\
\hline FC: Highway & $-0.85^{* * *}$ & $(-6.86)$ & $-0.78 * * *$ & $(-7.29)$ & $-0.84^{* * *}$ & $(-3.81)$ & $-0.87 * * *$ & $(-4.17)$ \\
\hline FC: Railway & 0.05 & $(1.03)$ & $0.12^{* * *}$ & $(3.79)$ & 0.09 & $(1.21)$ & $0.12^{*}$ & $(2.00)$ \\
\hline CT: Port & $0.57^{* * *}$ & $(4.04)$ & $0.95^{* * *}$ & $(10.29)$ & $0.75^{* * *}$ & $(21.19)$ & $0.63^{* * *}$ & $(5.90)$ \\
\hline GDP importer & $0.83^{* * *}$ & $(4.33)$ & $-0.23^{* * *}$ & $(-9.27)$ & $0.96^{* * *}$ & $(23.03)$ & $1.02^{* * *}$ & $(78.22)$ \\
\hline GDP pc importer & $0.43^{* *}$ & $(2.46)$ & $1.23^{* * *}$ & $(43.66)$ & $-0.18^{* *}$ & $(-2.35)$ & $0.52^{* * *}$ & $(15.25)$ \\
\hline Year dummies & Yes & & Yes & & Yes & & Yes & \\
\hline Importer dummies & & & Yes & & Yes & & Yes & \\
\hline Constant & $-11.50^{* * *}$ & $(-3.58)$ & 2.10 & $(1.19)$ & $-9.56^{* * *}$ & $(-8.89)$ & $-14.34^{* * *}$ & $(-6.80)$ \\
\hline observations & 948 & & 360 & & 396 & & 132 & \\
\hline chi2 & 4320.38 & & & & & & & \\
\hline chi2_c & 1482.61 & & & & & & & \\
\hline Tests & & & Stat. & $p$-value & Stat. & $p$-value & Stat. & $p$-value \\
\hline Hausman test & & & 17.99 & 0.3243 & 22.95 & 0.1150 & 29.11 & 0.0232 \\
\hline Sargan-Hansen(robust) & & & 24.888 & 0.0004 & 24.660 & 0.0004 & 106.946 & 0.0000 \\
\hline Heteroscedasticity test & & & 5135.04 & 0.0000 & 2558.32 & 0.0000 & 189.01 & 0.0000 \\
\hline Wooldridge test & & & 73.632 & 0.0000 & 14.853 & 0.0005 & 33.228 & 0.0002 \\
\hline Friedman's test & & & 6.933 & 1.0000 & 3.690 & 1.0000 & 4.175 & 0.9391 \\
\hline Mean VIF & & & 3.56 & & 3.30 & & 4.39 & \\
\hline
\end{tabular}

$z$ or $t$ statistics in parentheses; ${ }^{*} p<0.1,{ }^{* *} p<0.05,{ }^{* * *} p<0.01$; CT is container throughput;

FC is freight carried; GDP pc stands for GDP per capita.

These findings are rather important indicating that the impact of the explanatory variables included in the gravity equation could be inaccurately estimated if the pair-wise heterogeneity biases in both intercept and slope terms are not accounted for during the econometric estimation of the model. In particular, in the presence of country-pair heterogeneity in both intercept and slope terms, our empirical results shown that parameter estimates tend to be underestimated for country-pairs with higher trade volume and overestimated for those country-pairs with lower trade volume. Specifically in Table 1, the parameter estimates of most independent variables in Asia gravity model tend to be smaller in the magnitude than those in the random-coefficient model, and verse vice for those in the Europe model. Hence, as explained by Tzouvelekas ${ }^{[18]}$, in 
the absence of any economic a priori arguments for believing that the parameters of the gravity equation are the same across trading partners, the stochastic varying coefficient gravity model seems to be a more appropriate specification. Generally, those findings suggest that unless heterogeneity is accounted for correctly in both intercept and slope terms, standard gravity models could yield biased results.

The coefficients two measures of road transport costs and port efficiency are -0.85 and 0.57 respectively and of the expected signs. Specifically, a $10 \%$ increase in road transport costs may reduce trade value of China's port cities by $8.5 \%$. In reality, a large amount of cargo is transported by truck in China. It shows that a very high proportion of cost is incurred on the movement from inland provinces to coastal ports. In addition, our result suggests that a $10 \%$ increase in port efficiency yields $5.7 \%$ of the export value. Previous literature ${ }^{[6,23]}$ also suggest that port efficiency is an effective way significantly facilitating a country's exports. Blonigen and Wilson ${ }^{[23]}$ estimated that a $10 \%$ increase in port efficiency leads to approximately an $8 \%$ increase in a port's share of U.S. imports. It suggests that the great gains could be yielded form the improvements in those two transportation area.

The coefficient of railroad costs is not of the expected sign and not statistically significant at $10 \%$ level. It is expected since freight carried by railroad is still a smaller one in China. In reality, a large amount of cargo is transported by truck. Specifically, freight goods transported by truck account for about $84 \%$, on contrary, only $2 \%$ by train ${ }^{[17]}$. For example, on average, freight carried by railway in Shanghai from 1995 to 2010 is only about 11 million tons whereas freight carried by road is as high as 300 million tons. The figures are similar for other port cities. The reason for the positive sign of railroad costs variable is probably because that railroad transport mode facilitates goods movements in inland at a much lower cost, about one quarter of transport costs by truck ${ }^{[2]}$. From a government policy perspective, the railroad transport mode is a feasible way to address the congestion problems of the road transport system in China.

The GDP per capita of the exporter and importer in the models is interpreted as a proxy for the capita-endowment ratio. The coefficient of GDP per capita of the exporter is -0.36 , statistically significant at $1 \%$ level. Generally, the negative sign suggests that merchandise exports from China tend to be of labor-intensive manufactured products ${ }^{[24]}$. This is especially the case for an export country like China, where a great share of export tends to be processing and manufacturing trade. In addition, the coefficient of importer's GDP per capita is 0.43 and positive and statistically significant at $5 \%$ level, consistent with the empirical results in previous literature.

Additionally, the GDP per capita of exporters can be interpreted as good measures of supply of exports ${ }^{[2]}$. For a labor-intensive export country, it should be interpreted as the direct cost of manufactures and is expected to be an appropriate proxy of its average wage. Clark et al. ${ }^{[7]}$ also used manufacturing wage as a proxy of GDP per capita in their model. For comparison, we also introduce the average wage of export city as a proxy of GDP per capita. Table 2 presents comparison of results with different proxies for GDP per capita of exporter. The coefficient of exporter's average wage is -0.23 , a little smaller in magnitude than the one of GDP per capita, suggesting that the average wage of port city is an appropriate proxy for GDP per capita. 
Table 2 Comparison of results with different proxies for gdp per capita of exporter

\begin{tabular}{|c|c|c|c|c|c|c|}
\hline Variable & $(1)$ & & $(2)$ & & (3) & \\
\hline GDP exporter & $1.24^{* * *}$ & $(2.87)$ & $1.16^{* * *}$ & $(2.84)$ & $0.77^{*}$ & $(1.78)$ \\
\hline GDP pc exporter & $-0.36^{* * *}$ & $(-2.90)$ & & & & \\
\hline Wage of exporter & & & $-0.23^{*}$ & $(-1.90)$ & & \\
\hline Population exporter & & & & & $0.68^{* *}$ & $(2.30)$ \\
\hline FC: Highway & $-0.85^{* * *}$ & $(-6.86)$ & $-0.78^{* * *}$ & $(-6.83)$ & $-1.31^{* * *}$ & $(-4.06)$ \\
\hline FC: Railway & 0.05 & $(1.03)$ & 0.04 & $(0.85)$ & -0.03 & $(-0.71)$ \\
\hline CT: Port & $0.57^{* * *}$ & $(4.04)$ & $0.54^{* * *}$ & $(3.86)$ & $0.68^{* * *}$ & $(4.23)$ \\
\hline GDP importer & $0.83^{* * *}$ & $(4.33)$ & $0.83^{* * *}$ & $(4.28)$ & $0.84^{* * *}$ & $(4.27)$ \\
\hline GDP pc importer & $0.43^{* *}$ & $(2.46)$ & $0.39^{* *}$ & $(2.34)$ & $0.40^{* *}$ & $(2.40)$ \\
\hline Year 1999 & $-0.16^{* *}$ & $(-2.01)$ & -0.14 & $(-1.64)$ & $-0.18^{* *}$ & $(-2.37)$ \\
\hline Year 2000 & $-0.21^{* * *}$ & $(-2.66)$ & $-0.16^{* *}$ & $(-2.29)$ & $-0.23^{* * *}$ & $(-2.88)$ \\
\hline Year 2001 & $-0.18^{* *}$ & $(-2.37)$ & $-0.13^{* *}$ & $(-2.03)$ & $-0.20 * * *$ & $(-2.75)$ \\
\hline Year 2002 & $-0.28^{* * *}$ & $(-2.81)$ & $-0.23^{* * *}$ & $(-2.81)$ & $-0.30 * * *$ & $(-3.80)$ \\
\hline Year 2003 & $-0.28^{* * *}$ & $(-3.54)$ & $-0.23^{* * *}$ & $(-3.32)$ & $-0.29^{* * *}$ & $(-3.64)$ \\
\hline Year 2004 & $-0.17^{* *}$ & $(-2.10)$ & $-0.14^{*}$ & $(-1.75)$ & $-0.18^{* *}$ & $(-2.49)$ \\
\hline Year 2005 & -0.10 & $(-1.58)$ & -0.10 & $(-1.43)$ & $-0.14^{* *}$ & $(-2.01)$ \\
\hline Constant & $-11.50^{* * *}$ & $(-3.58)$ & $-12.27^{* * *}$ & $(-3.76)$ & $-16.60^{* * *}$ & $(-4.61)$ \\
\hline Observations & 948 & & 948 & & 948 & \\
\hline chi2 & 4320.38 & & 3886.44 & & 4822.33 & \\
\hline chi2_c & 1482.61 & & 1456.50 & & 1593.93 & \\
\hline
\end{tabular}

$z$ statistics in parentheses

${ }^{*} p<0.1,{ }^{* *} p<0.05,{ }^{* * *} p<0.01$

Dependent variable: log value of export in real US\$.

GDP pc stands for GDP per capita. CT is container throughput. FC is freight carried.

In our gravity model, the coefficient of exporter's population is 0.68 . Although it is statistically significant at $5 \%$ level, its sign is opposite to that of GDP per capital. In addition, unlike the introduction of average wage, replacing the GDP per capita by population of exporter significantly changes the magnitude of other variables' estimating coefficient. In a panel framework, the confusing sign for the population variable is mainly because of the fact that population variable, unlike other economic variables, changes slightly with time, with a very small variance in most cases. Therefore, it is more like a time-invariable variable. It is also the case in our data set. On average, the population of the four port cities is about 78.75 million, whereas the standard deviation is only around 3.21 million. Oguledo and Macphee ${ }^{[25]}$ also confirmed that the coefficient estimation for population of importers and exporters may be negatively or positively signed. 


\section{Conclusions}

The purpose of this paper is to quantitatively investigate the effect of transportation system on trade flows of four major port cities in China. In light of the fact that country-pair heterogeneities in both intercept and slope terms are important factors in explaining bilateral trade flows between China and the other countries. This paper introduces a random-coefficients model for parameters estimation, which allows for modeling the heterogeneity in the functional relationship between dependent variable and independent variables. The empirical findings are rather important indicating that the impact of the explanatory variables included in the gravity equation could be inaccurately estimated if the pair-wise heterogeneity biases in both intercept and slope terms are not accounted for during the econometric estimation of the model. In addition, those findings suggest that unless heterogeneity is accounted for correctly in both intercept and slope terms, standard gravity models could yield biased results.

The empirical results reveal that a $10 \%$ increase in road transport costs may reduce trade value of China's port cities by $8.5 \%$. Also, a $10 \%$ increase in port efficiency yields $5.7 \%$ of the export value. It implies that the improvement transportation system in port cities of China offers greater scope for its trade competitiveness. In addition, the overall estimated elasticity of the three transport modes is 1.36 , which is almost six times that of the average wage of port cities. It suggests that upgrading China's transport service networks should offer the greater scope for maintaining and increasing its competitive edge in low cost productions. It is a possible avenue to a more export share in the world trade. Given China's trade patterns are unlikely to change dramatically and China's world export share continue to grow in the short to medium run. The transportation service would need to remain accommodative to this patterns and growth, which are important long-run contributors to China's export success.

\section{References}

[1] Ge Y. Globalization and industry agglomeration in China. World Development, 2009, 37(3): 550-559.

[2] Xu L Z, Fang S C, Zhang X. Transport costs and China's exports: some empirical evidences. Journal of Systems Science and Complexity, 2013, 26(3): 365-382.

[3] Limão N, Venables A J. Infrastructure, geographical disadvantage and transport costs. The World Bank Economic Review, 2001, 15(3): 451-479.

[4] Irwin D A, Terviö M. Does trade raise income? Evidence from the twentieth century. Journal of International Economics, 2002, 58: 1-18.

[5] Bougheas S, Demetriadesb P O, Morgenrothc E L W. Infrastructure, transport costs, and trade. Journal of International Economics, 1999, 47: 169-189.

[6] Wilson J S, Mann C L, Otsuki T. Trade facilitation and economic development: A new approach to quantifying the impact. The World Bank Economic Review, 2003, 17(3): 367-389.

[7] Clark X, Dollar D, Micco A. Port efficiency, maritime transport costs and bilateral trade. National Bureau of Economic Research Working Paper, 2004, No. 10353.

[8] Xu L Z, Wang S Y. Analysis and forecasting of container port systems: Based on TEI@I methodology. Beijing: Science Press, 2014.

[9] Tinbergen J. Shaping the world economy. New York: Twentieth Century Fund, 1962.

[10] Egger P, Pfaffermayr M. The proper panel econometric specification of the gravity equation: A three-way model with bilateral interaction effects. Empirical Economics, 2003, 28(3): 571-580.

[11] Cheng I H, Wall H J. Controlling for heterogeneity in gravity models of trade and integration. Federal Reserve Bank of St. Louis Review, 2005, 87(1): 49-63. 
[12] Baltagi B H, Egger P, Pfaffermayr M. A generalized design for bilateral trade flow models. Economics Letters, 2003, 80(3): 391-397.

[13] Mátyás L. The gravity model: Some econometric considerations. The World Economy, 1998, 21(3): 397-401.

[14] Anderson J E, Van Wincoop E. Gravity with gravitas: A solution to the border puzzle. American Economic Review, 2003, 93: 170-192.

[15] Egger P. An econometric view on the estimation of gravity models and the calculation of trade potentials. The World Economy, 2002, 25: 297-312.

[16] Swamy P A V B. Efficient inference in a random coefficient regression model. Econometrica, 1970, 38(2): 311-323.

[17] Ma L, Zhang J. Infrastructure development in a fast-growing economy: The People's Republic of China. Infrastructure's Role in Lowering Asia's Trade Costs, 2009: 182.

[18] Tzouvelekas V. Accounting for pairwise heterogeneity in bilateral trade flows: A stochastic varying coefficient gravity model. Applied Economics Letters, 2007, 14(12): 927-930.

[19] Johnston J, DiNardo J. Econometric Methods. New York: McGraw-Hill, 1997.

[20] Greene W. Econometric Analysis. New York: Prentice-Hall, 2000.

[21] Baier S L, Bergstrand J H. The growth of world trade: Tariffs, transport costs, and income similarity. Journal of International Economics, 2001, 53: 1-27.

[22] Hoechle D. Robust standard errors for panel regressions with cross-sectional dependence. The Stata Journal, 2007, 7(3): 281-312.

[23] Blonigen B A, Wilson W W. New measures of port efficiency using international trade data. National Bureau of Economic Research Working Paper, 2006, No. 12052.

[24] Bergstrand J H. The generalized gravity equation, monopolistic competition, and the factor-proportions theory in international trade. Review of Economics and Statistics, 1989, 71(1): 143-153.

[25] Oguledo V I, MacPhee C R. Gravity models: A reformulation and an application to discriminatory trade arrangements. Applied Economics, 1994, 26(2): 107-120. 